\title{
A INFORMAÇÃO DE MODA SEM GÊNERO NAS POSTAGENS DO INSTAGRAM: UMA PROPOSTA ANALÍTICA A PARTIR DAS TEORIAS DOS ATOS DE FALA
}

\author{
Iracema Tatiana Ribeiro Leite Justo/UFPE
}

Hans da Nóbrega Waechter (orientador)/UFPE

\section{RESUMO}

A informação de moda nas redes sociais é relevante para observação das construções dos sujeitos. Considerando que as roupas são as primeiras formas de significação que direciona as representações de gênero, este artigo propõe um instrumento de análise para compreender os discursos das marcas de moda sem gênero nas postagens do instagram, tendo como aporte teórico as teorias dos atos de fala de Austin (1990) e performatividade proposta por Butler (2018). Esta pesquisa aborda as narrativas visuais apresentadas pelas marcas compreendendo as ideologias presentes a partir das linguagens visuais (imagem) e verbais (textos nas postagens e hashtags).

Palavras-chave: Informação de moda. Moda sem gênero. Identidade de gênero. Teorias dos atos de fala.

\section{Introdução}

O presente artigo busca refletir teoricamente sobre as mensagens presentes nos discursos da moda sem gênero na mídia social instagram, observando as mensagens visuais e verbais a partir das postagens das marcas de moda, traçando um caminho de pesquisa para análise do discurso.

A teoria utilizada para compreensão das identidades aqui utilizada é a performatividade de gênero apontada por Judith Butler. Conforme Butler:

Em outras palavras, atos, gestos e desejo produzem o efeito de um núcleo ou substância interna, mas o produzem na superfície do corpo, por meio do jogo de ausências significantes, que sugerem, mas nunca revelam, o princípio organizador da identidade como causa. Esses atos, gestos e atuações, entendidos em termos gerais, são performativos, no sentido de que a essência ou identidade que, por outro lado, pretendem expressar são fabricações manufaturadas e sustentadas por signos corpóreos e outros meios discursivos (BUTLER, 2003, p. 194).

Em síntese Butler (2003), apresenta que os atos repetitivos através da linguagem corporal (vestimenta, gestos, atuações) naturalizam a representação dos sujeitos conforme seu sexo biológico. 
Ou seja, que as constituições dos sexos e dos gêneros são práticas culturais impostas num sistema heteronormativo, e quem não se enquadra na binaridade feminina e masculina, que a sociedade estabelece como constitutivo do comportamento causal do sexo biológico, é excluído da sociedade. Por exemplo, no design de moda, antes mesmo de os sujeitos nascerem, já se estabelecem narrativas binárias de papéis de gênero, através da configuração do vestuário, como constituintes das características femininas e masculinas.

Assim, o objeto de estudo desta pesquisa são os discursos das marcas sem gênero nas postagens do Instagram e a perspectiva da comunicação da moda, enquanto linguagem em seus enunciados. Para tanto são trazidas, como escopo teórico-analítico, as teorias de Austin (1990) e Butler (2003) que entendem a linguagem como uma ação performativa . Neste caso, o sistema da moda seria uma das agências que "negocia" com os sujeitos sociais as identidades na interação entre os atores sociais com seus símbolos e significados.

A hashtag \#modasemgênero foi utilizada como ferramenta para escolher as marcas de moda sem gênero e afunilar a pesquisa. A hashtag é compreendida como uma linguagem virtual e um destaque para determinadas palavras com teor informativo, uma vez que é colocada nas redes sociais como uma chamada para determinado assunto ou tema. Para Gorini (2017, p.8):

\begin{abstract}
a hashtag é uma forma de marcar um discurso, através de palavras-chave, tags, e fazê-lo circular para além do texto em si, com uma finalidade que não se encerra em si mesma, ou seja, a relação que se estabelece a partir da palavrachave nos textos que a reproduzem pode ser vista como uma forma de conectar pessoas de diferentes procedências, (não apenas geográfica), em um texto comum. E assim revelam-se também os processos de identificação que conectam o texto: a pessoa que escreveu ou compartilhou, (curtiu ou comentou), o assunto que está sendo abordado e a hashtag em questão.
\end{abstract}

Para análise foram escolhidas 02 marcas sem gênero, tendo como requisito inicial o perfil com mais de 1.000 seguidores.

\title{
Moda, identidade e ideologia
}

Ao se discorrer sobre moda sem gênero, é importante a compreensão da moda e o seu papel social. O jogo das aparências pode ser considerado uma das forças motrizes da moda, onde os corpos são vestidos para representar identidade(s), sejam individuais ou coletivas, com seus simbolismos e crenças, em consonância com as mudanças na contemporaneidade. 
Para Le Breton (2007, p. 7) “o corpo é o vetor semântico pelo qual a evidência da relação com o mundo é construída". Por meio do corpo, o vestuário estabelece várias narrativas cujos significados são construídos e estabelecidos culturalmente (LEITE, 2011). Essa geração de sentido inscritas no corpo a partir do vestuário são sistemas sociais que desempenham papeis de relações de poder, seja hegemônico ou não. Esse discurso mostra o caráter efêmero do corpo e sua inscrição cultural, onde as relações de poder são determinantes para a construção social dos papéis sociais binários de gênero.

Dessa forma, as roupas envolvidas nesses processos não apenas refletem um padrão de consumo, mas também são responsáveis pela criação e manutenção de uma série de signos no contexto em que são inseridas, com ideologias, que vão desde inclusão social à representação da identidade, não só de gênero, mas de grupo, de classe social, entre outras. Para Marcondes:

\begin{abstract}
A ideologia é uma forma de dominação, gerando uma falsa consciência, uma consciência ilusória, que se produz através de mecanismos pelos quais se torna parte (ideias da classe dominante) pelo todo (a realidade como ela é), ou seja, pelos quais se objetificam certas representações (a da classe dominante) como sendo uma verdadeira realidade, tudo isso produzindo uma aparente legitimação das condições existentes numa determinada sociedade em um período histórico determinado (MARCONDES, 2000, p.121).
\end{abstract}

Bourdieu (2012) aponta também que " as ideologias servem de interesses particulares que tendem a apresentar como interesses universais, comuns ao conjunto do grupo e contribui para uma falsa consciência das classes dominadas e a legitimação da ordem por meio das distinções (hierarquias) e para legitimação destas distinções."

Ao abranger a imagem de moda como texto, os conteúdos gerados correspondem a uma fonte de entendimento de como os grupos sociais e a própria sociedade manifestam sua consciência sobre as construções identitárias e que artifícios e mudanças estão ocorrendo dentro de determinados grupos, além da repercussão desse conteúdo para a sociedade.

As marcas de modas em gênero constroem um discurso de desconstrução da forma tradicional de ver os gêneros através das representações inscritas no vestuário, de forma a refletir sobre a não binaridade.

O sistema da moda é um agente de inclusão e promoção da diversidade (Schneid e Barreto ,2016, p. 13), sendo relevante refletir sobre os enunciados propostos pelas marcas de moda sem gênero, uma vez que funcionam como agentes ou sujeitos da ação, ou seja, performatizando novos conceitos a partir de suas postagens com suas mensagens verbais e visuais. 
Considera-se, a princípio, que a tendência de moda sem gênero está relacionada a um engajamento ideológico, a partir do momento que a marca se apresenta com ideias sobre a não binaridade dos gêneros, propondo um desejo de respeito pelo outro, através de seu sistema de sinais e significados, e que um grupo de pessoas são atraídas e se sentem pertencentes a este discurso.

Bourdieu (2012), em suas pesquisas, reitera a força do poder hegemônico onde as mudanças sociais são lentas e questiona o ato de submissão e aceitação de como as sociedades são construídas, ou seja, o sistema educacional, igrejas e escolas, dentre outros, a princípio, exerce este poder e influencia a formação das identidades. Entretanto, é relevante avaliar que na era da comunicação virtual, os indivíduos estão cada vez mais se posicionando contra o sistema vigente e demarcando novas fronteiras simbólicas, buscando firmar suas identidades sociais e de gênero. Resumidamente, na moda sem gênero, supõe-se que exista um signo ideológico, que por ser compreensível por uma coletividade, atua na produção de sentido.

\section{Teoria dos atos de fala de Austin}

No entendimento de Austin (1990), através de normas, regras, os signos são compreendidos por um grupo de pessoas. Marcondes (2000, p 132) considera que "as comunicações contêm a possibilidade de reinterpretação não só do que é dito, o nível de esclarecimento linguístico, mas também da própria situação de discurso, isto é, do contexto e dos seus elementos constitutivos". Então, as palavras seriam uma representação de como as pessoas manifestam suas opiniões, em determinadas experiências de vida, e fatores como quem está proferindo determinadas palavras, gestos corporais, atitudes, etc. Desse modo tudo deve ser considerado, em todo o contexto, para observação da ação dessas palavras.

A abordagem pragmática defendida por Austin (1990) apresenta a teoria da performatividade, em que as palavras são ações e estão relacionadas a determinados contextos, às convenções de uso e às intenções dos falantes. Marcondes (2000, p.67) fala "que toda ação pressupõe um agente, no sentido que toda ação é ação de um agente e o agente se define como todo aquele que realiza a ação."

No contexto dos performativos, Austin (1990) classifica as sentenças em atos locucionários, ilocucionários e perlocucionários. Assim, Austin $(1990$, p.95) fala que "a esse ato de "dizer algo", na acepção normal e completa, chamo de realização de um ato locucionário, e ao estudo dos proferimentos desse tipo e alcance, chamo de estudo de locuções, ou de unidades completas do discurso." O autor (ibdem, p. 103) complementa "o ato locucionário que tem um significado; o ato 
ilocucionário que tem uma certa força ao dizer algo; e o ato perlocucionário que consiste em se obter certos efeitos pelo fato de se dizer algo."

Sintetizando as palavras de Austin, Marcondes (2000, p.129) afirma que "o ato locucionário vem a ser o proferimento de uma determinada sentença da língua, com sentido e referências determinados, a dimensão linguística do ato de fala; o ato ilocucionário é o ato de fazer algo através deste proferimento; o ato perlocucionário diz respeito às consequências, não convencionais, que um ato de fala pode gerar."

Complementando a relação dos enunciados e a fala-ação, Ribeiro (2015) diz que "os enunciados possuem cargas semânticas que vão além das palavras: as inferências, o contexto, as convenções socias, as intenções do falante, a percepção do ouvinte etc ". Portato, é neste intuito que o presente artigo entende a imersão das linguagens a partir das palavras e imagens enquanto força ilocucinária, dentro das redes sociais, que é um lugar de fala e de interação, performatiza novos valores e crenças sociais.

A partir dessas reflexões teóricas, serão considerados os discursos da moda sem gênero na rede social instagram, levando em conta a performatividade de gênero propostas pelas marcas.

\section{Metodologia}

A presente pesquisa é um recorte de pesquisa do doutorado em andamento. O método utilizado é qualitativo, traçando uma visão metodológica para análise do discurso, utilizando as teorias dos atos de fala de Austin (1990) como caminho da proposta de análise. As linguagens visuais e verbais associadas às imagens das marcas de moda farão parte da análise, para se entender os códigos visuais da moda sem gênero que dão sentido ao processo de comunicação.

\section{Análises e discussões}

Adaptando o modelo teórico proposto por Austin (1990), consideram-se aqui as mensagens verbais e visuais atreladas às postagens das marcas como um enunciado perfomativo. Portanto, ressalta-se que a teoria dos atos de fala é um arcabouço teórico, que foi adaptado como uma forma de pensar e analisar o discurso. Neste caso, as postagens das marcas sem gênero foram coletadas a partir do hashtag \#modasemgênero, e as narrativas das marcas foram agrupadas em atos locucionários, ilocucionários e perlocucionários. 
Exemplificando a análise, na postagem de acordo com a figura 1, as locuções, seriam os hashtags \#modasemgênero e outros hashtags associados, com palavras como: autêntico, afrobrazilian, moda consciente, moda despojada. A ilocução seria a ação descrita a partir dos hashtags, enfatizadas pelos textos vinculados à imagem: " menos padrões, mais liberdade para ser quem você quiser ser". Já o locutor, aqui é colocado como a marca de moda, o agente que envia a mensagem através das postagens.

A manifestação da ação (ilocução) é vista tanto pelas mensagens verbais, através das palavras destacadas nos hashtags e a imagem a partir do vestuário, gestualidade, postura, cabelo, dentre outros elementos da linguagem visual, atuam juntos na ação performativa.

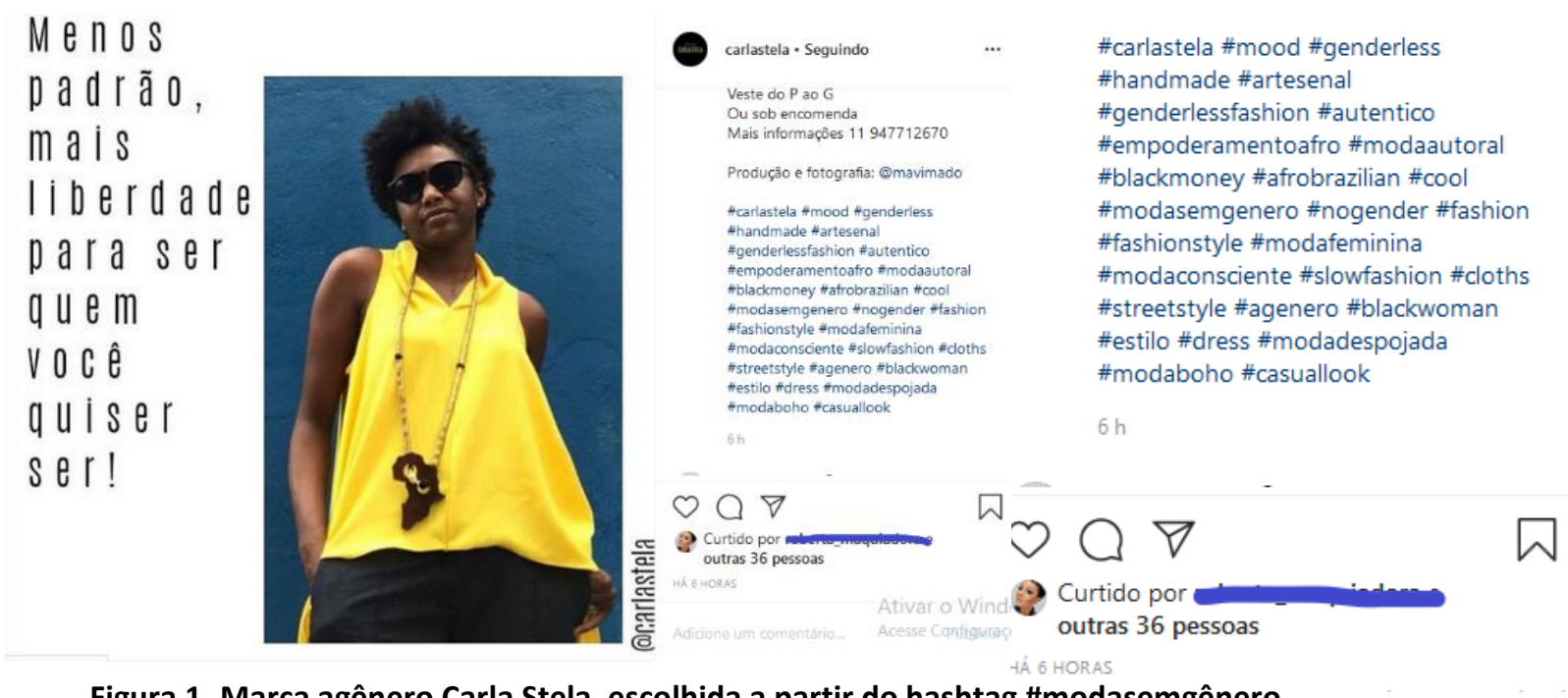

Figura 1- Marca agênero Carla Stela, escolhida a partir do hashtag \#modasemgênero Fonte: Instagram.

Analisando a imagem acima (figura 1) a partir da linguagem visual, destaca-se que o vestuário proposto é uma blusa amarela solta ao corpo sem estampa. A fotografia parece ter sido tirada de baixo para cima, de forma que a pessoa fotografada parece estar olhando para baixo, passando uma idéia de empoderamento (\#empoderamentoafro). Os acessórios utilizados, sobretudo o colar, é um mapa da África, os cabelos e tom de pele também estão relacionados às palavras destacadas ao hashtags, que propõe uma moda fora dos padrões hegemônicos.

$\mathrm{Na}$ figura 2, a partir da proposta metodológica, as locuções seriam as hashtags relacionadas: \#modaconsciente, modasemgenero, \#costuracriativa, \#diversidade, \#exclusividade, \#consumoconsciente, dentre outros. 


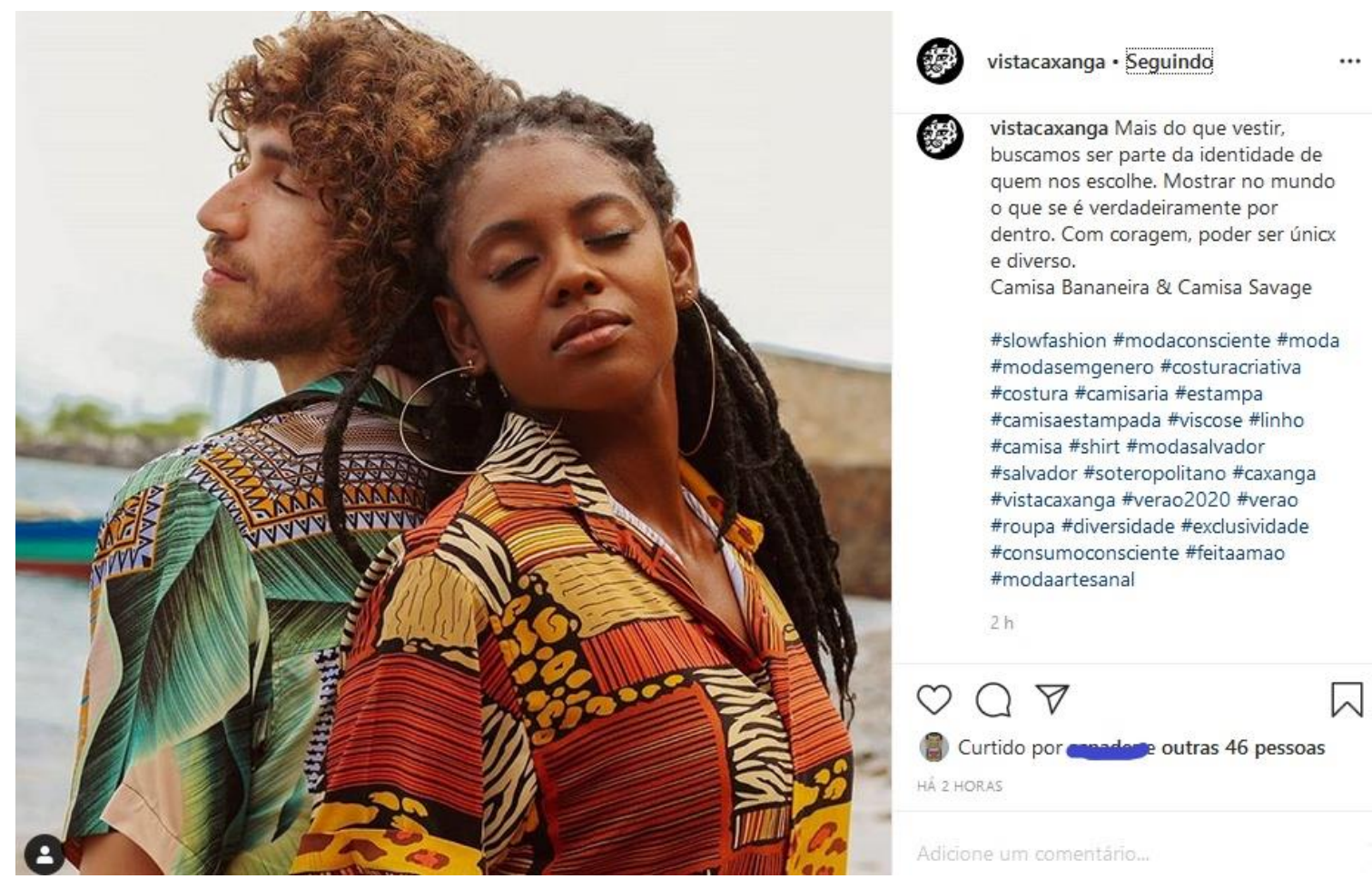

Figura 2- Marca Vista Caxangá através do hashtag \#modasemgênero

Fonte: Instagram

A ilocução seria a ação descrita a partir destas palavras "mais do que vestir, buscamos ser parte da identidade de quem nos escolhe, mostrar no mundo o que se é verdadeiramente por dentro. Com coragem, poder ser único e diverso. " Como linguagem visual da ilocução está a imagem com a sua mensagem visual a partir das linguagens visuais (cor, textura, forma, gestual, postura, cabelo, acessórios).

Na descrição da imagem, têm-se uma figura feminina e outra masculina com características étnicas diferentes, estampas tropicais com cores quentes e frias nas camisas (como opostos), tecido em linho, os corpos são posicionados um apoiado no outro de formas opostas.

Para finalizar, a perlocução seriam os resultados advindos dessa ação que são visualizados pela interação da marca com os usuários consumidores, sobretudo, através de curtidas e comentários.

Conclui-se que as postagens apresentadas têm a sua força performativa, uma vez que os textos, que iniciam as postagens, apresentam a ideologia da marca, que desestabiliza as formas binárias de significação. No entanto, de uma forma geral e preliminar, o que se observa é que ambas as postagens ainda trabalham com características binárias. Na postagem 1, têm-se a hashtag \#modasemgênero, 
mas também \#modafeminina, que é uma classificação binária. Já, na postagem 2, a imagem é uma constituição binária de oposição masculino e feminino, em que os corpos femininos e masculinos são colocados como opostos e complementares.

Logo, os exemplos indicados são um caminho para análise do discurso de moda, para compreender a informação de moda disseminada pelas marcas de moda sem gênero, pontuando que a mudança na forma de ver os gêneros a partir da roupa já faz parte de um discurso na contemporaneidade, mas que ainda está em um momento de firmamento, e que as forças hegemônicas ainda se constituem nos textos e imagens disseminados.

\section{Conclusão}

Este estudo traz um percurso de pesquisa ainda incipiente, que mostra a importância de se compreender estes signos visuais e verbais, direcionando a análise do discurso e as teorias dos atos de fala, para se analisar o simbolismo entre as representações de gênero e as ações envolvidas em defesa da inclusão de gênero fora da heteronormatividade e do poder hegemônico ao qual as sociedades são condicionadas.

Ao considerar as hashtags uma ferramenta discursiva, propõe-se analisar detalhadamente, não apenas, as palavras destacas, mas todo o contexto envolvido na relação entre sujeito-marca de moda, sujeitos-sujeitos (grupos sociais) e as imagens associadas para esta representação que ancoram as palavras ou vice-versa. Quando a marca de moda se funde a uma ideologia a partir de seus signos linguísticos e visuais, tem-se uma ação responsiva, uma vez que a mesma exerce sobre seus seguidores, uma provocação ou mesmo reflexão sobre as questões de gênero a partir da moda sem gênero.

Em relação aos exemplos utilizados para observação do discurso da moda, percebe-se que as peças do vestuário constituem-se peças simples e que já existem no Mercado de moda, portanto o discurso da moda está evidenciado a partir das palavras, mostrando os sujeitos vestidos com atitudes, postura, gestual, ressignificando tais peças. Portanto, em relação à ideologia que prega a não binaridade, as hashtags das postagens da marca apresentam-se contraditórias, ao evidenciar palavras binárias em sua descrição, tais como na figura 1 \#modafeminina. Já, na figura 2, a binaridade está na própria imagem na oposição feminino-masculino. 


\section{Referências}

AUSTIN, J. L. Quando dizer é fazer. Palavras e ação. Trad. Danilo Marcondes Souza Filho. Artes Médicas. Porto Alegre, 1990.

BAKHTIN, M. (V. N. Volochínov). Marxismo e filosofia da linguagem. Problemas fundamentais do método sociológico na ciência da linguagem. Tradução, notas e glossário Sheila Grillo e Ekaterina Vólkova Américo; ensaio introdutório de Sheila Grillo - São Paulo: Editora 34, 1a Edição, 2017.

BOURDIEU, Pierre. O poder simbólico. 16 edição. Rio de Janeiro: Bertrand Brasil, 2012.

BUTLER, J. Problemas de gênero: Feminismo e subversão da identidade. Rio de Janeiro: Ed. Civilização Brasileira, 2003.

GORINI. Paula. Hashtag em Disputa: Um Estudo Sobre Identidade e Memória Nas Redes Sociais. In: Encontro nacional de história da mídia. São Paulo, 2017.

LE BRETON, D. A sociologia do corpo 2. ed. tradução de Sônia M.S. Fuhrmann. Petrópolis: Rio de Janeiro, 2007.

LEITE, I.T.R. Vestuário e feminilidade: uma análise da relação vestuário e feminilidade nas capas da revista Manequim nos seus 50 anos de Publicação. Dissertação mestrado. UFPE: Recife, 2011.

MARCONDES. Danilo. Desfazendo mitos sobre a pragmática. In: ALCEU. V. 1 ALCEU - v.1 - n.1 -pg 38 a 46,2000

RIBEIRO, C. B. Gêneros discursivos e atos de fala no facebook: uma análise de posts e memes relacionados às eleições para a presidência do brasil em 2014. Dissertação de mestrado. Universidade de Lisboa, 2015.

SCHNEID E BARRETO. Moda sem gênero: representação de identidade e diversidade no vestuário. In: 13o Colóquio DE MODA, 2017. 